\title{
含窒素複素環式カルベンを触媒とする効率的有機合成法の開発研究
}

\author{
鈴木由美子
}

\section{Development of C-C Bond Formation and Asymmetric Reactions Catalyzed by $N$-Heterocyclic Carbenes}

\author{
Yumiko SUZUKI \\ School of Pharmaceutical Sciences, University of Shizuoka, 52-1 Yada, \\ Suruga-ku, Shizuoka 422-8526, Japan
}

(Received April 7, 2008)

\begin{abstract}
$N$-Heterocyclic carbenes have been studied for their ability to catalyze $\mathrm{C}-\mathrm{C}$ bond formations and asymmetric reactions. The fluoro groups of fluorobenzenes are nucleophilically substituted with aroyl groups derived from aromatic aldehydes due to the catalytic action of imidazolidenyl carbenes to afford ketones. $N$-Heterocyclic carbenes mediate the addition of trimethylsilyl cyanide to aldehydes to yield cyanohydrin trimethylsilyl ethers. The use of chiral imidazolidenyl carbenes derived from $(R, R)$-1,3-bis [(1-naphthyl)ethyl]imidazolium chloride led to enantioselective cyanosilylation. $C_{2}$-symmetric imidazolidenyl carbenes catalyze the asymmetric acylation of racemic secondary alcohols.
\end{abstract}

Key words $-N$-heterocyclic carbene; nucleophilic aroylation; cyanosilylation; asymmetric acylation; kinetic resolution; organocatalyst

\section{1.はじめに}

含窒素複素環式カルベン ( $N$-heterocyclic carbene; NHC）はへテロ原子により安定化された一重項力 ルベンで特異な挙動を示す。1960 年代に Wanzlick によりその存在は提唱されていたが, ${ }^{1-3)}$ Arduengo らにより 1991 年に初めて単離同定が報告された。 カルベン中心炭素原子は 2 つ電子の入つた $\mathrm{sp}^{2}$ 軌道 とそれに直交した空の $\mathrm{p}$ 軌道を持ち，この空の $\mathrm{p}$ 軌道へのヘテロ原子孤立電子対からの電子供与によ りカルベンが安定化する (Scheme 1). 5,6)

触媒としての機能の発見は 20 世紀半ばにまでさ かのぼる. 1943 年に鵜飼らはアゾリウム塩が塩基 性条件下ベンゾイン縮合反応を触媒すると報告し

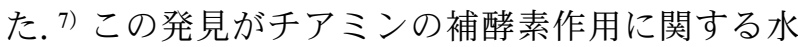
原らの先駆的な研究8) と Breslow による作用機構の

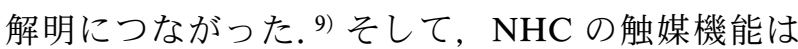
20 世紀末から 21 世紀初頭にかけての有機触媒分野

静岡県立大学薬学部（干422-8526 静岡市駿河区谷田 52-1)

e-mail: suzuyumi@u-shizuoka-ken.ac.jp

本総説は, 平成 19 年度日本薬学会東海支部学術奨励賞 の受賞を記念して記述したものである.
の急速な発展とともに大きく注目されるようになつ た．古くから知られているベンゾイン縮合反応及び Stetter 反応に加え，近年 NHC を触媒とするエステ ル基転移反応やホモエノラート反応など多くの報告 がある. ${ }^{10-14)}$ さらに, 光学活性 NHC を用いること によりこれらは不斉反応へと展開されている. ${ }^{11,13,14)}$ 筆者は NHC の特異な有機触媒能に着目し，その分

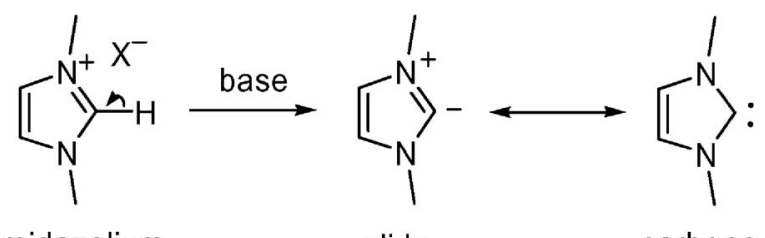
imidazolium ylide carbene

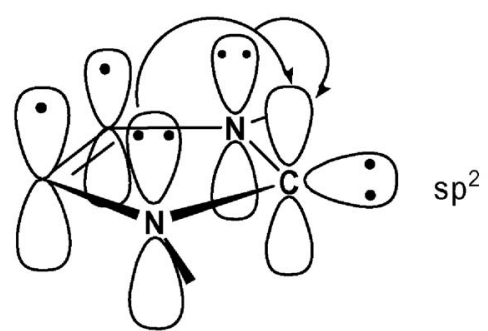

Scheme 1. Preparation of NHC and Stabilizing Effects 
子設計と有機合成への利用を継続して検討してき た. ${ }^{15)}$ 本総説では, 近年の研究成果のうちべンゼン 環上への求核的アロイル化反応，アルデヒドのシア ノシリル化反応，そして，第二級アルコールの不斉 アシル化反応について述べる.

\section{2. ベンゼン環上への求核的アロイル化反応}

宮下及び筆者はアゾリウム塩 1,2 から生じる NHC が電子欠乏性複素環上クロロ基の芳香族アル デヒド由来アロイル基への置換反応を触媒すること を報告した（Fig. 1).16-22）この反応はベンゾイン縮 合と共通の “Breslow 中間体 3” を経る求核置換反 応である。

同様の置換反応が 4-chloronitrobenzene などのべ ンゼン誘導体においても可能と予想されるが，実際 にこの反応を行ってみると, 置換体は得られるもの の収率は非常に低かった。一方，4-fluoronitrobenzene はアロイル化反応が速やかに進行しベンゾフ エノン誘導体を与えた (Table 1). ${ }^{23)}$ その他の電子<smiles></smiles>

1<smiles>Cn1c[n+](C)c2ccccc21</smiles>

2<smiles>CN1C=CN(C)C1=C(O)Br</smiles>

Breslow intermediate 3
Fig. 1. NHC Precursors and the Breslow Intermediate
吸引性基の結合したフルオロベンゼン類においても 置換反応が進行した。 反応機構を Scheme 2 に示し た。この求核的アロイル化反応を用いれば，緩和な 条件下, 脱離基の置換した電子吸引基の $p$ 位に位 置特異的に一段階でアロイル基を導入することがで きる．古典的なアシル化法である Friedel-Crafts 反 応は親電子反応であり, ベンゼン環の電子欠乏部位 にアロイル基を導入することは不可能である．現在 多くのフルオロベンゼンが市販されており，本反応 はベンゾフェノン誘導体の合成法として Friedel-

Table 1. Aroylation of Fluorobenzenes

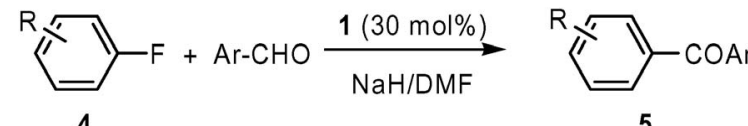

5

\begin{tabular}{ccccc}
\hline \hline Entry & $\mathrm{R}$ & $\mathrm{Ar}$ & Condition $^{a)}$ & Yield (\%) \\
\hline 1 & $4-\mathrm{NO}_{2}$ & $\mathrm{Ph}$ & $\mathrm{A}$ & 57 \\
2 & $4-\mathrm{NO}_{2}$ & $4-\mathrm{ClC}_{6} \mathrm{H}_{5}$ & $\mathrm{~A}$ & 61 \\
3 & $4-\mathrm{NO}_{2}$ & $4-\mathrm{MeOC}_{6} \mathrm{H}_{5}$ & $\mathrm{~A}$ & 77 \\
4 & $4-\mathrm{NO}_{2}$ & $3-\mathrm{FC}_{6} \mathrm{H}_{5}$ & $\mathrm{~A}$ & 63 \\
5 & $4-\mathrm{NO}_{2}$ & $2-\mathrm{FC}_{6} \mathrm{H}_{5}$ & $\mathrm{~A}$ & 49 \\
6 & $4-\mathrm{CN}$ & $\mathrm{Ph}$ & $\mathrm{B}$ & 37 \\
7 & $4-\mathrm{C}_{6} \mathrm{H}_{5} \mathrm{CO}$ & $\mathrm{Ph}$ & $\mathrm{B}$ & 32 \\
8 & $2-\mathrm{F}-4-\mathrm{NO}_{2}$ & $\mathrm{Ph}$ & $\mathrm{C}$ & 75 \\
9 & $2-\mathrm{F}-4-\mathrm{NO}_{2}$ & $3-\mathrm{ClC}_{6} \mathrm{H}_{5}$ & $\mathrm{C}$ & 56 \\
10 & $2-\mathrm{F}-4-\mathrm{NO}_{2}$ & $3-\mathrm{MeOC}_{6} \mathrm{H}_{5}$ & $\mathrm{D}$ & 60 \\
\hline
\end{tabular}

a) $\mathrm{A}: 0^{\circ} \mathrm{C}, 1 \mathrm{~h}, \mathrm{~B}: 0^{\circ} \mathrm{C}, 20 \mathrm{~min}$ and then r.t., $2 \mathrm{~h}, \mathrm{C}: 0^{\circ} \mathrm{C}, 1.5 \mathrm{~h}, \mathrm{D}:-15$ ${ }^{\circ} \mathrm{C}, 30 \mathrm{~min}$, and then r.t., overnight.

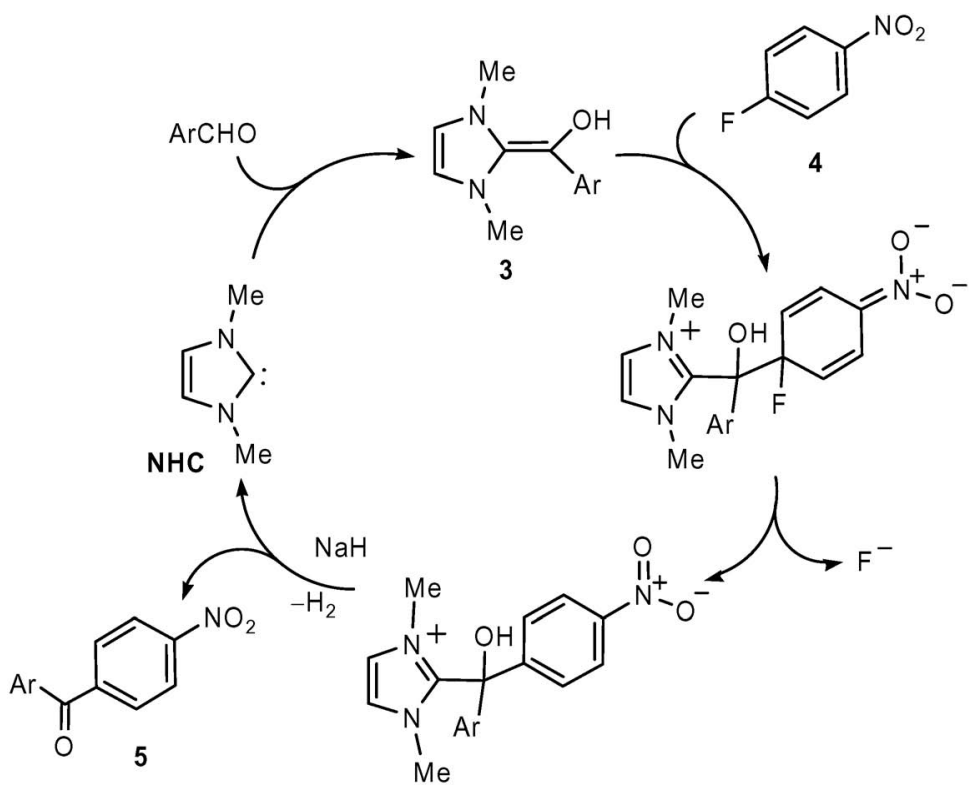

Scheme 2. Reaction Mechanism 
Crafts 反応と相補的に用いることができる.

このベンゼン環上への求核的アロイル化反応を複 素環合成に利用した（Scheme 3). ${ }^{24}$ 本反応で合成 したベンゾフェノン誘導体と各種求核試薬との反応 により二環性あるいは三環性の複素環が合成でき た。 ヒドラジンとの反応ではインダゾール 6 が，そ して水酸化ナトリウムとの反応によりキサントン類 7，アミンとの反応によりアクリドン類 $\mathbf{8}$ が生成し た。これら複素環骨格を持つ化合物には生物活性を 示すものが多く知られている。ベンゼン環上への求 核的アロイル化反応は生物活性化合物の合成に広く 応用可能と期待される.

\section{3. アルデヒドのシアノシリル化反応}

筆者は含窒素複素環式カルベンを触媒としてアル デヒドとトリメチルシリルシアニドを反応させると シアノシリル化反応が進行することを他の研究グ ループとときを同じくし， ${ }^{25-27)}$ 独自に見い出し た. ${ }^{28)}$ Song ら, ${ }^{25)}$ 青山ら, ${ }^{26)}$ 丸岡ら ${ }^{27)}$ はケトンのシ アノシリル化も進行することを報告している.

イミダゾリウム塩 9 を塩基で処理して調製した NHC（5 mol\%）の THF 溶液にアルデヒド及びト リメチルシリルシアニドを加えることでシアノシリ ル化が進行する（Table 2)，反応液は酸で処理さ れ，生成物はシアノヒドリンとして単離された。

また, 初めて光学活性な複素環式カルベンを用い ることにより不斉シアノシリル化反応に応用した (Scheme 4)。 $C_{2}$-対称性イミダゾリウム塩 $(R, R)-\mathbf{1 0}$ から NHC を生成させシアノシリル化反応を行う と，選択性は低いが不斉シアノシリル化反応が進行 した。生成物の脱シリル化体，シアノヒドリン類は $\alpha$-ヒドロキシ酸， $\beta$-ヒドロキシアミンなどの有用な 化合物へと容易に変換可能であり，重要な合成中間 体である，金属錯体を触媒とする不斉シアノシリル 化反応の報告例は多くあるが，非金属化合物を触媒 とする反応例はごくわずかである. ${ }^{29)}$

Table 2. Cyanosilylation of Aldehydes Using Imidazolium Salt 9

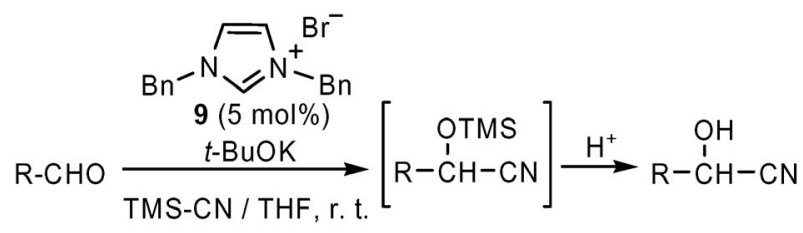

Entry<smiles>[R]c1cccc(C(=O)c2ccc([N+](=O)[O-])cc2F)c1C(=O)c1ccc([N+](=O)[O-])c(F)c1</smiles>

Scheme 3. Syntheses of Heterocyclic Compounds 

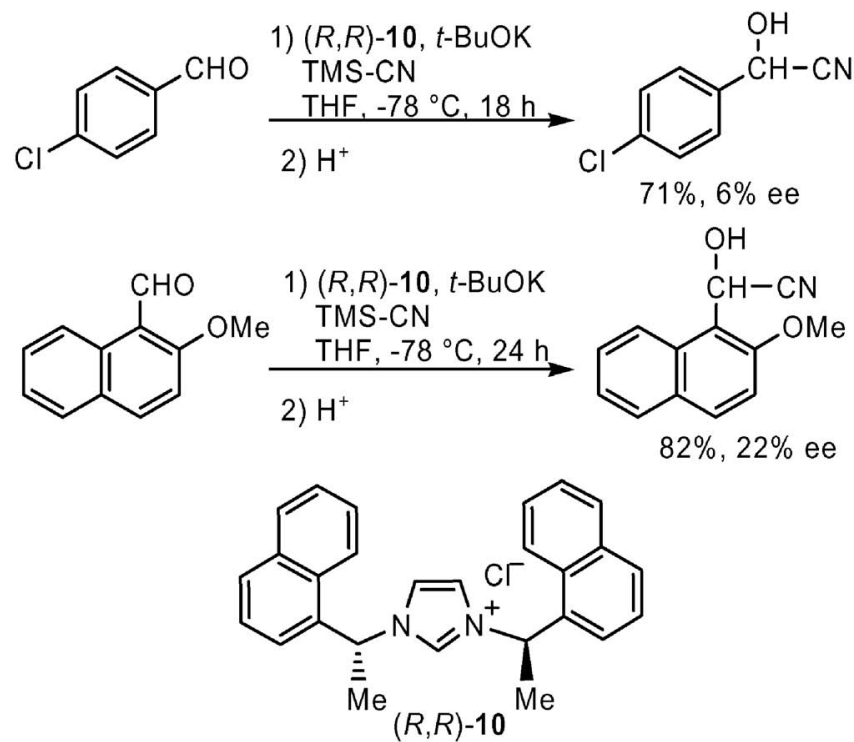

Scheme 4. Enantioselective Cyanosilylation

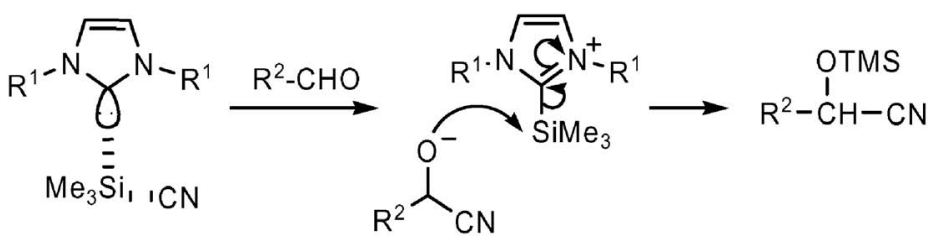

Scheme 5. Postulated Reaction Mechanism 1

筆者は NHC 触媒によるシアノシリル化反応の反 応機構として，2 種類の機構を提唱した. ${ }^{28)} 1$ つは NHC がケイ素原子に求核攻撃しシリル化剂を活性 化させ反応が進行するという機構である（Scheme 5)。アジリジンの開環反応, ${ }^{30)}$ 向山アルドール反 応 ${ }^{31)}$ に関しても，NHCのシリル化合物活性化作用 による機構が提唱されている．もう 1 つはベンゾイ ン縮合反応と共通の中間体を経て進行する機構であ る (Scheme 6)。すなわち，NHCがアルデヒドに 求核攻撃し生成した付加体とシアノシリル化剂が反 応する. 青山らも同様の二機構を提案している. ${ }^{26)}$ Scheidt らは NHC 触媒による $\alpha$-ヒドロキシプロバ ギルシランのアルデヒドへの付加反応において， シ アノシリル化の場合と同様の 2 種類の機構が考えら れると述べている. ${ }^{32)}$

\section{4. 第二級アルコールの不斉アシル化反応}

NHC を触媒とするアシル基転移反応／アシル化 反応は，2002 年に Nolan ら, ${ }^{33)}$ 及び Hedrick ら ${ }^{34)}$ のそれぞれ独立した研究グループから報告がなされ た。この報告の中で Hedrick らは反応中間体とし

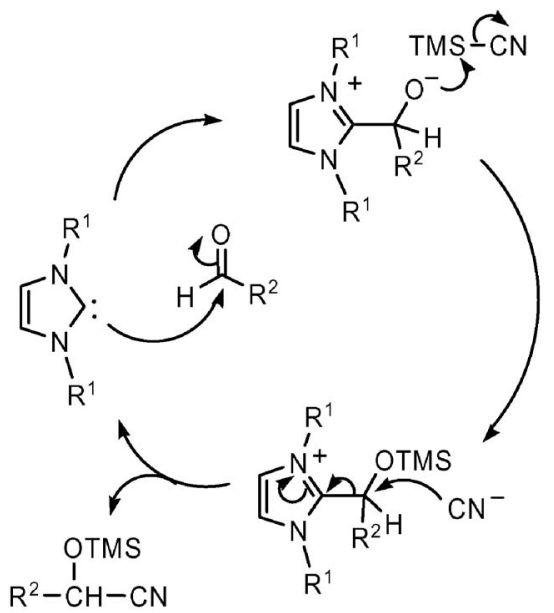

Scheme 6. Postulated Reaction Mechanism 2

て 2-アシルイミダゾリウム塩 11 を推定している (Fig. 2)。すなわち，NHC とエステルから 11 が生 成し，これにアルコールが求核攻撃することでアシ ル基が転移する．筆者は，この反応に光学活性な NHC を用いれば不斉アシル化が進行し，第二級ア ルコールの速度論的分割が可能と考えた。 
そこで，第二級アルコールの速度論的分割を目指 し，光学活性 NHC を用いて不斉アシル化を検討し た（Table 3). ${ }^{35,36)}$ 種々の $C_{2}$-対称性イミダゾリウム 塩を用いて 12 のアシル化反応を行った結果，イミ ダゾリウム塩窒素原子側鎖上の置換基 $\mathrm{R}$ が立体的 に嵩高いとき反応の選択性が向上する傾向があるが, $\mathrm{R}$ が嵩高過ぎると反応活性の低下を招くことが分か

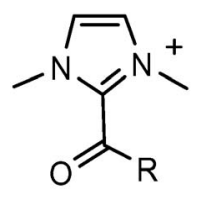

11

Fig. 2. 2-Acylimidazolim
つた。また，NHC の前駆体は塩化物よりも四フッ 化ホウ素酸塩を用いたときにアシル化速度が大きい という結果が観察された.

アシル化剂に種々のビニルエステル類を用いて反 応を検討した (Table 4)。直鎖飽和酸ビニルエステ ルは䣷酸ビニルに比べ高い不斉収率を示したが，安 息香酸ビニル，不飽和酸ビニルエステル，酷酸イソ プロペニルを用いた場合には逆に選択性が低下し た。 丸岡らは筆者と同一構造の NHC を触媒とし, 立体的に嵩高いジフェニル酢酸ビニルを用いること で高選択的に不斉アシル化が進行することを報告し ている. ${ }^{37)}$

なお，アシル基転移反応の機構に関しては, NHC が Br $\varphi$ nsted 塩基として働き，アルコールを活性化

Table 3. Asymmetric Acylation of $\mathbf{1 2}$ Catalyzed by $C_{2}$-symmetric NHCs

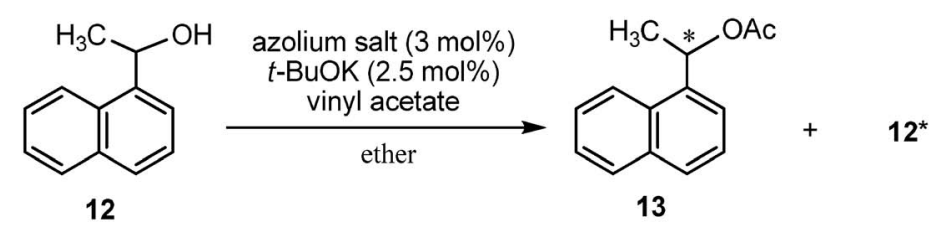

\begin{tabular}{|c|c|c|c|c|c|c|c|c|}
\hline \multirow{2}{*}{ Entry } & \multicolumn{2}{|c|}{ Azolium salt } & \multirow{2}{*}{ Condition } & \multicolumn{2}{|c|}{ Acetate } & \multicolumn{2}{|c|}{ Alcohol } & \multirow{2}{*}{$s$} \\
\hline & & $\mathrm{X}$ & & Yield $\left.(\%)^{a}\right)$ & $\mathrm{ee}(\%)^{b)}$ & Yield $\left.(\%)^{a}\right)$ & ee $(\%)^{b)}$ & \\
\hline 1 & $(R, R)-\mathbf{1 0}$ & $\mathrm{Cl}$ & r.t., $2 \mathrm{~d}$ & 21 & $42(R)$ & 69 & $21(S)$ & 3.0 \\
\hline 2 & $(R, R)-\mathbf{1 0}$ & $\mathrm{Cl}$ & $0^{\circ} \mathrm{C}, 2 \mathrm{~d}$ & 21 & $51(R)$ & 79 & $11(S)$ & 3.4 \\
\hline 3 & $(R, R)-\mathbf{1 4}$ & $\mathrm{Cl}$ & r.t., $18 \mathrm{~h}$ & 15 & $19(S)$ & 83 & $1(R)$ & 1.5 \\
\hline $4^{c)}$ & $(R, R)-\mathbf{1 5}$ & $\mathrm{Cl}$ & r.t., $16 \mathrm{~h}$ & 52 & $18(R)$ & 47 & $17(S)$ & 1.7 \\
\hline 5 & $(R, R)-16$ & $\mathrm{BF}_{4}$ & $0^{\circ} \mathrm{C}, 1 \mathrm{~d}$ & 33 & $45(R)$ & 56 & $22(S)$ & 3.3 \\
\hline 6 & $(R, R)-16$ & $\mathrm{BF}_{4}$ & $-15^{\circ} \mathrm{C}, 3 \mathrm{~d}$ & 14 & $58(R)$ & 85 & $8(S)$ & 4.1 \\
\hline 7 & $(R, R)-17$ & $\mathrm{BF}_{4}$ & $0^{\circ} \mathrm{C}, 18 \mathrm{~h}$ & 43 & $14(R)$ & 47 & $14(S)$ & 1.5 \\
\hline 8 & $(R, R)-\mathbf{1 8}$ & $\mathrm{BF}_{4}$ & $0^{\circ} \mathrm{C}, 2 \mathrm{~d}$ & 6 & $23(R)$ & 80 & $5(S)$ & 1.7 \\
\hline $9^{c)}$ & $(R, R)-19$ & $\mathrm{BF}_{4}$ & r.t., $4 \mathrm{~d}$ & 17 & $50(R)$ & 83 & - & - \\
\hline $10^{c)}$ & $(R, R)-\mathbf{2 0}$ & $\mathrm{BF}_{4}$ & $0^{\circ} \mathrm{C}, 2.5 \mathrm{~d}$ and then r.t., $2 \mathrm{~h}$ & 4 & $13(R)$ & 84 & $<1$ & - \\
\hline 11 & $(R, R)-21$ & $\mathrm{BF}_{4}$ & $0^{\circ} \mathrm{C}, 12 \mathrm{~h}$ & 27 & $49(R)$ & 73 & $20(S)$ & 3.5 \\
\hline 12 & $(S, S)-\mathbf{2 2}$ & $\mathrm{BF}_{4}$ & $0^{\circ} \mathrm{C}, 18 \mathrm{~h}$ & 37 & $39(S)$ & 60 & $23(R)$ & 2.8 \\
\hline
\end{tabular}

a) Isolated yield. $b$ ) Enantioselectivities were measured by HPLC using a Chiralcel OD column or a Chiralpac AS column. $c$ ) $1.0 \mathrm{M}$ THF solution of ${ }^{t} \mathrm{BuOK}$ was used.<smiles>[R]C(C)n1cc[n+]([C@H]([Z])C)c1</smiles>

$(R, R)-14: \mathrm{X}=\mathrm{Cl}, \mathrm{R}=$ cyclohexyl $(R, R)-15: \mathrm{X}=\mathrm{Cl}, \mathrm{R}=$ phenyl $(R, R)-16: \mathrm{X}=\mathrm{BF}_{4}, \mathrm{R}=1$-naphthyl $(R, R)$-17: $\mathrm{X}=\mathrm{BF}_{4}, \mathrm{R}=2$-naphthyl
$(R, R)$-18: $\mathrm{X}=\mathrm{BF}_{4}, \mathrm{R}=$ 9-anthryl $(R, R)-19: \mathrm{X}=\mathrm{BF}_{4}, \mathrm{R}=1$-anthryl $(R, R)-20: \mathrm{X}=\mathrm{BF}_{4}, \mathrm{R}=1$-(2-methoxynaphthyl)

$(R, R)-21: \mathrm{X}=\mathrm{BF}_{4}, \mathrm{R}=1$-pyrenyl<smiles>Cc1c2ccccc2cc2ccccc12</smiles>

9-anthry<smiles>Cc1cccc2cc3ccccc3cc12</smiles>

1-anthryl

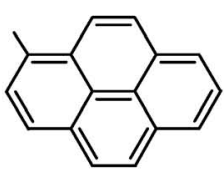

1-pyrenyl<smiles>[R]C(C)[n+]1ccn([CH-][O-])c1</smiles>

$(S, S)-22$ :

$R=$ 9-phenanthryl<smiles>Cc1cc2ccccc2c2ccccc12</smiles>

9-phenanthryl 
Table 4. Asymmetric Acylation of $\mathbf{1 2}$ with Various Acyl Donors

\begin{tabular}{|c|c|c|c|c|c|c|c|c|}
\hline Entry & Acyl donor & $\mathrm{R}^{1}$ & $\mathrm{R}^{2}$ & Condition & $\begin{array}{l}\text { Ester } \\
\text { ee }(\%)\end{array}$ & $\begin{array}{l}\text { Alcohol } \\
\text { ee }(\%)\end{array}$ & $\begin{array}{c}\text { Conversion } \\
(\%)\end{array}$ & $s$ \\
\hline 1 & Vinyl acetate & $\mathrm{Me}$ & $\mathrm{H}$ & $\mathrm{A}^{a)}$ & 48 & 16 & 27 & 3.3 \\
\hline 2 & Vinyl benzoate & $\mathrm{Ph}$ & $\mathrm{H}$ & $\mathrm{A}^{a)}$ & 33 & 17 & 34 & 2.3 \\
\hline 3 & Vinyl propionate & Et & $\mathrm{H}$ & $\mathrm{A}^{a)}$ & 68 & 16 & 19 & 6.1 \\
\hline 4 & Vinyl butyrate & $\operatorname{Pr}$ & $\mathrm{H}$ & $\mathrm{A}^{a)}$ & 66 & 11 & 14 & 5.4 \\
\hline 5 & Vinyl crotonate & & $\mathrm{H}$ & $\mathrm{B}^{b)}$ & 34 & 11 & 24 & 2.3 \\
\hline 6 & Vinyl methacrylate & $\mathrm{Me}$ & $\mathrm{H}$ & $\mathrm{A}^{a)}$ & 11 & 24 & 68 & 1.5 \\
\hline 7 & Isopropenyl acetate & $\mathrm{Me}$ & $\mathrm{Me}$ & $\mathrm{B}^{b)}$ & 14 & 16 & 47 & 1.5 \\
\hline
\end{tabular}

a) $(R, R)-16$ (3 mol\%), $t$-BuOK (2.5 ml\%), and ether were used. $b)(R, R)-16(5 \mathrm{~mol} \%), t$-BuOK $(5 \mathrm{ml} \%)$, and THF were used.

させて反応を触媒する機構が Movassaghi ら ${ }^{38)}$ 及び $\mathrm{Hu}$ ら $^{39)}$ によって提案されている.

\section{5. おわりに}

以上のように，NHC を触媒として用いる炭素— 炭素結合形成反応及び光学活性体を利用した不斉合 成への応用研究を紹介した。現在求核的アロイル化 に関しては反応の効率化に成功し，数 $\mathrm{mol} \%$ の触媒 量でも高収率で反応が進行することを見い出してい る. ${ }^{40)}$ また，この反応を用いたキサントン骨格を有 する天然物の合成も検討中である.

この数年間で NHC を触媒として用いる反応が次 々と報告されてきた。最近では，NHC 触媒反応の 天然物全合成などへの利用例もみられるようになつ た。この分野のさらなる進展に大きく貢献できるよ う，今後の研究を展開していきたい.

\section{謝辞本論文で紹介した研究成果は共同研究者} のご協力によりなし得たものです．特に筆者ととも に熱心に実験を遂行した学生諸氏に感謝致します。 本研究を始める機会を与え，ご指導下さった恩師宮 下 晶先生に深く感謝致します。また, 筆者の研究 を忍耐強く見守り，終始有益なご助言・ご指導を下 さいました静岡県立大学薬学部教授・佐藤雅之先生 に厚くお礼申しあげます。

\section{REFERENCES}

1) Wanzlick H.-W., Schikora E., Angew. Chem., 72, 494 (1960).

2) Wanzlick H.-W., Kleiner H.-J., Angew. Chem., 73, 493 (1961).

3) Wanzlick H.-W., Angew. Chem., 74, 129-134 (1962).

4) Arduengo III, A. J., Harlow R. L., Kline M. A., J. Am. Chem. Soc., 113, 361-363 (1991).

5) Arduengo III, A. J., Acc. Chem. Res., 32, 913-921 (1999)

6) Herrmann W. A., Kocher C., Angew. Chem. Int. Ed. Engl., 36, 2162-2187 (1997).

7) Ukai T., Tanaka R., Dokawa S., J. Pharm. Soc. Jpn., 63, 296-300 (1943).

8) Mizuhara S., Handler P., J. Am. Chem. Soc., 76, 571-573 (1954).

9) Breslow R., J. Am. Chem. Soc., 80, 37193726 (1958).

10) " $N$-Heterocyclic Carbenes in Synthesis," ed. by S. P. Nolan, WILEY-VCH Verlag GmbH \& Co. KGaA, Weinheim, 2006.

11) Enders D., Balensiefer T., Acc. Chem. Res., 37, 534-541 (2004).

12) Nair V., Bindu S., Sreekumar V., Angew. Chem. Int. Ed., 43, 5130-5135 (2004).

13) Marion N., Díez-González S., Nolan S. P., Angew. Chem. Int. Ed., 46, 2988-3000 
(2007)

14) Enders D., Niemeier O., Henseler A., Chem. Rev., 107, 5606-5655 (2007).

15) Suzuki Y., J. Syn. Org. Chem. Jpn., 66, 377386 (2008).

16) Higashino T., Takemoto M., Miyashita A., Hayashi E., Chem. Pharm. Bull., 33, 13951399 (1985).

17) Miyashita A., Matsuda H., Iijima C., Higashino T., Chem. Pharm. Bull., 38, 1147-1152 (1990)

18) Miyashita A., Matsuda H., Iijima C., Higashino T., Chem. Pharm. Bull., 40, 43-48 (1992).

19) Miyashita A., Matsuda H., Suzuki Y., Iwamoto K., Higashino T., Chem. Pharm. Bull., 42, 2017-2022 (1994).

20) Miyashita A., Obae K., Suzuki Y., Iwamoto K., Oishi E., Higashino T., Heterocycles, 45, 2159-2173 (1997).

21) Miyashita A., Suzuki Y., Iwamoto K., Higashino T., Chem. Pharm. Bull., 46, 390-399 (1998).

22) Miyashita A., Suzuki Y., Iwamoto K., Oishi E., Higashino T., Heterocycles, 49, 405-413 (1998).

23) Suzuki Y., Toyota T., Imada F., Sato M., Miyashita A., Chem. Commun., 2003, 13141315.

24) Suzuki Y., Toyota T., Miyashita A., Sato M., Chem. Pharm. Bull. 54, 1653-1658 (2006).

25) Song J. J., Gallou F., Reeves J. T., Tan Z., Yee N. K., Senanayake C. H., J. Org. Chem., 71, 1273-1276 (2006).
26) Fukuda Y., Maeda Y., Ishii S., Kondo K., Aoyama T., Synthesis, 4, 589-590 (2006) .

27) Kano T., Sasaki K., Konishi T., Mii H., Maruoka K., Tetrahedron Lett., 47, 46154618 (2006).

28) Suzuki Y., Md. A. B., Muramatsu K., Sato M., Tetrahedron, 62, 4227-4231 (2006).

29) Tian S.-K., Hong R., Deng L., J. Am. Chem. Soc., 125, 9900-9901 (2003).

30) Wu J., Sun X., Ye S., Sun W., Tetrahedron Lett., 47, 4813-4816 (2006).

31) Song J. J., Tan Z., Reeves J. T., Yee N. K., Senanayake C. H., Org. Lett., 6, 1013-1016 (2007)

32) Reynolds T. E., Stern C. A., Scheidt K. A., Org. Lett., 9, 2581-2584 (2007).

33) Grasa G. A., Kissling R. M., Nolan S. P., Org. Lett., 4, 3583-3586 (2002).

34) Nyce G. W., Lamboy J. A., Connor E. F., Waymouth R. M., Hedrick J. L., Org. Lett., 4, 3587-3590 (2002).

35) Suzuki Y., Yamauchi K., Muramatsu K., Sato M., Chem. Commun., 2004, 2770-2771.

36) Suzuki Y., Muramatsu K., Yamauchi K., Sato M., Tetrahedron, 62, 302-310 (2006).

37) Kano T., Sasaki K., Maruoka K., Org. Lett., 7, 1347-1349 (2005).

38) Movassaghi M., Schmidt M. A., Org. Lett., 7, 2453-2456 (2005) .

39) Lai C.-L., Lee H. M., Hu C.-H., Tetrahedron Lett., 46, 6265-6270 (2005).

40) Suzuki Y., Ota S., Fukuta Y., Ueda Y., Sato M., J. Org. Chem., 73, 2420-2423 (2008). 